\title{
El costo socioeconómico del consumo de drogas ilícitas en Chile
}

\author{
Matias Fernández $H$.
}

RESUMEN

En el presente artículo se estima la magnitud de los recursos monetarios que pierde o deja de producir Chile debido al tráfico y consumo de drogas ilícitas. Sobre la base de la metodología de "costo de enfermedad", se obtiene que la carga económica que representó para Chile el consumo de drogas ilícitas en el año 2006 alcanzó a los 266.744 millones de pesos —es decir, 503 millones de dólares en moneda corriente de dicho año- equivalentes al $0,45 \%$ del producto interno bruto (PIB) de 2006 y a un costo per cápita de 16.232 pesos o 31 dólares. La mayor proporción de este monto se atribuye al control de delitos de drogas u otros cometidos por su causa (47\%) y a las reducciones de productividad ocasionadas por años de vida saludable perdidos (46\%).

PALABRAS CLAVE

CLASIFICACIÓN JEL

AUTOR
Drogas de uso indebido, consumo, tráfico de drogas, aspectos económicos, aspectos sociales, costos, prevención del delito, salud pública, productividad, medición, datos estadísticos, Chile

D62, J17, K42, H51

Matías Fernández H. es investigador y profesor instructor del Instituto de Sociología, Universidad Católica de Chile.mjfernan@uc.cl 


\section{I}

\section{Introducción}

En el presente artículo se estiman los costos socioeconómicos del consumo y tráfico de drogas ilegales en Chile durante el año 2006 -incluidos los costos en prevención y en salud, pérdidas de productividad y control del delito- con el objetivo de cuantificar monetariamente la magnitud de las externalidades negativas que la presencia de las drogas ilegales tiene para el país.

La necesidad de contar con un buen indicador de los costos socioeconómicos de uso y tráfico de drogas ilícitas radica en su capacidad para fundamentar y justificar adecuadamente decisiones e intervenciones públicas tendientes a reducir la magnitud de este flagelo. Single y otros (2003) especifican cuatro propósitos para esta clase de estudios:

i) las estimaciones económicas son útiles para dar una prioridad razonada a las políticas sobre drogas en la agenda pública;

ii) las estimaciones de calidad proveen un estándar que permite justipreciar las necesidades de intervención respecto de distintos problemas. Ante la ausencia de este estándar surge la tendencia a exagerar la relevancia de cada problema social por parte de los interesados;

iii) los estudios de costos sirven para focalizar áreas de intervención prioritarias e identificar las falencias de los sistemas nacionales de información, y muestran necesidades específicas de mejoramiento en los sistemas estadísticos nacionales, y

iv) dichos estudios permiten asimismo establecer una línea de base para evaluar las políticas y programas de drogas.

\section{A. Antecedentes}

Contar con un buen indicador de costos socioeconómicos del consumo de drogas ilícitas se ha vuelto un desafío prioritario en la última década, especialmente en países desarrollados que registran altas tasas de

$\square$ Este artículo forma parte de las investigaciones desarrolladas en el Núcleo Científico Milenio de Investigación Socioeconómica en Uso y Abuso de Drogas, financiado por el Ministerio de Desarrollo Social (ex MIDEPLAN). El autor agradece la ayuda recibida de Pilar Larroulet, Carlos Rodríguez y Eduardo Valenzuela. consumo (Pacula y otros, 2009). Sin embargo, son muy pocos los países en que se ha logrado desarrollar estimaciones de calidad, y las metodologías utilizadas difieren ampliamente entre ellas. Seguramente los estudios estadounidense (Oficina Nacional de Fiscalización de Drogas, 2004), canadiense (Rehm y otros, 2006) y australiano (Collins y Lapsley, 2008) son los más consolidados en la materia, aunque en Francia (Kopp y Philippe, 2006), España (García-Altés, Ollé y Colom, 2002) e Inglaterra y Gales (Godfrey y otros, 2002) también se han realizado estimaciones de altos estándares. En el contexto latinoamericano, la Comisión Interamericana para el Control del Abuso de Drogas (CICAD) de la Organización de los Estados Americanos ha encabezado el "Programa para estimar los costos humanos, sociales y económicos de las drogas en las Américas", con el propósito de promover esta clase de estudios en la región dando lugar a estimaciones de costos para la Argentina, Barbados, Chile, Costa Rica, El Salvador, México, el Perú y el Uruguay. Los resultados de estos estudios son, sin embargo, muy desiguales debido al excesivo uso de fuentes secundarias, a la indistinción de costos generados por alcohol respecto de los provocados por drogas ilícitas — agrupados bajo la categoría "sustancias psicoactivas"-, y a la ausencia de estimaciones adecuadas de costos indirectos. Pese a que estos problemas no afectan en la misma medida a todos estos estudios, las estimaciones a las que se llega no son del mejor nivel. No distinguir sustancias legales de ilegales es un problema basal que marca al conjunto de estos estudios, y que - como se argumentará- los margina del resto de las estimaciones internacionales.

\section{B. ¿Qué es un estudio de costos socioeconómicos del uso de drogas ilícitas?}

Los estudios de costos socioeconómicos del tráfico y uso de drogas ilícitas se enmarcan en la metodología de "costo de enfermedad" (COI, por sus siglas en inglés), en que se compara un escenario real, donde existe presencia de la enfermedad específica (tráfico y consumo de drogas en este caso) y sus consecuencias, con un escenario contrafactual en que la enfermedad no existiría (Kopp, 2001). Esta diferencia se cuantifica monetariamente. Lo que se estima de esta manera es la magnitud 
de los costos en que incurre el país debido al consumo de drogas ilícitas, los que no existirían en su ausencia.

Subyace así a este enfoque la noción de costo de oportunidad, es decir, una cuantificación de los costos en que se incurre al invertir los recursos en una determinada actividad (una enfermedad, en la perspectiva de COI) cuando podrían haber sido utilizados en otras actividades alternativas potencialmente disponibles (Rehm y otros, 2006). Un estudio de COI, entonces, cuantifica el monto de la reducción total en la producción de bienes y servicios que pueden ser atribuidos al desarrollo de una enfermedad (quantifying the amount of the total reduction in the production of goods and services which can be attributed to the development of an illness) (Kopp, 2001, pág. 26).

Una estimación de coI no debe confundirse con: i) un estudio de costos evitables, ii) un estudio de impacto presupuestario, o iii) un análisis de costo-beneficio. En primer lugar, a diferencia de un estudio de costos evitables, una estimación de COI no pretende cuantificar los recursos económicos que podrían ser "realmente" ahorrados mediante programas y políticas públicas efectivas. Mientras que los estudios de costos evitables buscan estimar la diferencia entre el escenario actual y un escenario hipotético que supone una tasa factible de éxito de una determinada intervención, una estimación de CoI contrasta el escenario actual con un escenario donde no existen, ni en el presente ni en el pasado, problemas vinculados al consumo de drogas ilícitas (Segel, 2006). En segundo lugar, un estudio de COI no mide la repercusión de una enfermedad en el presupuesto público, sino en el conjunto de la sociedad, incluidos ítems que trascienden el gasto público relacionado. Finalmente, a diferencia de los análisis de costo-beneficio, en las estimaciones de cor no se incorpora una cuantificación de los eventuales beneficios vinculados al consumo de drogas. Mientras que en el análisis costo-beneficio la pregunta es ¿qué pasaría si los costos asociados a un comportamiento singular $[. .$.$] terminaran a partir de$ hoy?) (what would happen if the costs associated with a particular behaviour [...] were to cease from today?), en un estudio de cor se compara la realidad con un escenario contrafactual donde el consumo nunca hubiese tenido lugar (Single y otros, 2003, págs. 21 y 22). Incluso si un determinado comportamiento como el consumo de drogas se detuviese inmediatamente, sus consecuencias seguirían teniendo efectos, siendo por lo tanto costos "inevitables". Por ello son excluidos en el análisis de costo-beneficio (Single y otros, 2003, pág. 22). Los estudios de COI, en cambio, sirven de soporte para el desarrollo de análisis de costo-beneficio.

\section{Limitaciones}

Pese a su utilidad, conviene tener siempre presente que la estimación de costos vinculados al consumo de drogas ilícitas es un ejercicio que presenta muchas limitaciones, y que dista bastante de ser una cuantificación real de un problema. Los resultados y los métodos de estimación muestran una cuantificación aparentemente exacta que conviene tomar con precaución. En primer lugar, la precisión de los estudios de costos depende de información que no se produce acabadamente ni siquiera en los países desarrollados. Por ello, es frecuente el uso de información secundaria y aproximaciones indirectas al problema, las que incluso al operar sobre supuestos razonables y debidamente justificados vuelven inciertos los resultados.

Una segunda limitación es la usual inexistencia de estudios sistemáticos sobre los efectos indirectos del consumo de drogas en otras conductas o enfermedades que generan costos. En Chile existe una estimación de fracciones etiológicas (o atribuibles) ${ }^{1}$ para los delitos cometidos a causa de la droga (Valenzuela y Larroulet, 2010), y una evaluación muy precaria de los "años de vida saludable" (AVISA) perdidos debido a la droga como factor de riesgo de enfermedades distintas de la drogodependencia (Escuela de Medicina, 2008). No existen, en cambio, estimaciones de fracciones etiológicas ni en salud (para la evaluación del costo de tratamiento de enfermedades parcialmente vinculadas al consumo de drogas ilícitas) ni en accidentes automovilísticos.

De ambos puntos se deduce una importante limitación “externa": pese al esfuerzo por generar una metodología unificada para la evaluación de cor por consumo de sustancias —esfuerzo realizado especialmente por Single y sus colegas en el Centro Canadiense sobre Abuso de Sustancias desde 1994 hasta 2001—, los distintos estudios desarrollados deben finalmente adecuarse a la información disponible en cada país, generando diferencias que los vuelven incomparables (Pacula y otros, 2009).

Sin embargo, la adecuada definición de una metodología es fundamental para realizar comparaciones en el tiempo, permitiendo evaluar al menos la evolución de los costos totales y de cada uno de sus ítems. La presente estimación representa un considerable avance en este sentido: se ha llegado a resultados bastante precisos para los ítems de pérdidas de productividad y

\footnotetext{
${ }^{1}$ Una fracción etiológica corresponde a la proporción de casos en que una "enfermedad" (el involucramiento delictual en este caso) puede ser atribuida a la exposición a un determinado factor de riesgo (el consumo de sustancias ilícitas).
} 
costos de control de drogas y delitos asociados, que son además los dos ítems de mayor importancia relativa. No obstante, la mayor deficiencia se encuentra en la radical subestimación de los costos directos que el consumo de drogas tiene sobre la salud y en la ausencia de toda estimación de costos indirectos en el mismo ítem. Por ello, la magnitud de costos estimada, una vez reajustada, deberá servir de base o "piso" para las futuras investigaciones en la materia que enmienden este defecto.

Idealmente, en la estimación se debiese haber considerado un período de tiempo más reciente, ya que cambios en los patrones de consumo o en el contexto institucional — como la entrada en vigencia de la ley de responsabilidad penal juvenil (RPJ) o la reestructuración del organismo encargado de la prevención de drogaspueden modificar el costo total del consumo de drogas ilícitas para Chile en los últimos años. La distancia en el tiempo, sin embargo, permite contar con información consolidada que no siempre se encuentra para períodos más recientes. Empero, un margen de retraso semejante presentan también diversas y prestigiosas estimaciones internacionales, con la excepción de Inglaterra y Gales (Godfrey y otros, 2002) y Australia (Collins y Lapsley, 2008), donde este margen se reduce a dos y tres años respectivamente.

Pese a las reconocidas falencias, los resultados representan un avance notorio respecto de las estimaciones previas del CONACE (2005) y Olavarría (2009). No obstante, el presente artículo debe mucho a este último. Las estimaciones para el ítem control son, además, de una precisión difícilmente igualable por las estimaciones internacionales publicadas hasta la fecha.

\section{II}

\section{Definiciones metodológicas básicas}

La definición de costos sociales utilizada en estudios de cor difiere de la usada comúnmente en economía: mientras que los costos sociales se refieren usualmente a la suma total de costos vinculados a un determinado comportamiento o decisión, aquí se entiende por costo social lo que se suele denominar "externalidad", concepto que implica la total exclusión de los costos privados. Los recursos que los consumidores destinan en el mercado de la droga no se consideran como costos sociales. Estos se refieren más bien a la carga socioeconómica impuesta "sobre" el conjunto de la sociedad por parte de agentes individuales que no incorporan estas consecuencias en su decisión de consumo (Single y otros, 2003, pág. 14). Los costos privados no generan intervenciones estatales puesto que: i) tienen su origen en una determinación enteramente voluntaria del individuo que toma la decisión de asumirlos (OEA/CICAD, 2006, pág. 18), siendo compensados por beneficios individuales de al menos igual magnitud, y ii) mientras no afecten a terceras personas, se supone que lo que es beneficioso para el individuo, lo es también para el conjunto de la sociedad. Además, el gasto en drogas de un agente es un recurso que recibe otro. Esta diferenciación es uno de los aspectos clave en que este artículo difiere del de Olavarría (2009).

La estimación no presenta mayores dificultades conceptuales y su estructura consiste en tres pasos sucesivos (Single y otros, 2003, pág. 14; OEA/CICAD, 2006):
- Identificación de las consecuencias adversas del abuso.

- Documentación y cuantificación del grado de causalidad entre el abuso y las consecuencias adversas.

- Asignación de costos a las consecuencias adversas. El primer paso se encuentra en principio bastante consensuado. El único aspecto en disputa es la inclusión o exclusión de costos intangibles, que se refiere a la carga emocional y física impuesta a las personas a causa de problemas inducidos por consumo de drogas (adicción, mortalidad prematura, o miedo al crimen y victimización) (refer to the emotional and physical burden placed on individuals because of drug-induced problems —addiction, premature mortality, or fear of crime and victimization-), y que pueden ser soportados tanto por el consumidor de drogas como por quienes lo rodean (Pacula y otros, 2009, pág. 6). Pese a que esta clase de costos podrían representar una magnitud importante en la carga total del consumo de drogas ${ }^{2}$, ellos son sumamente difíciles de cuantificar (Kopp, 2001, pág. 17; Segel, 2006, pág. 4; Single y otros, 2003, pág. 27) y las mediciones se encuentran muy poco estandarizadas. Por estas razones, en el contexto de drogas ilícitas solo

\footnotetext{
2 Collins y Lapsley (2008) estiman que los costos intangibles vinculados al consumo de drogas representan el $45 \%$ del total de costos socioeconómicos en Australia en los años 2004 y 2005.
} 
Collins y Lapsey (2008) los han incorporado debidamente. En Chile no existen los instrumentos para hacerlo.

El segundo paso puede ser más controversial. Inicialmente, permite discernir entre costos directos e indirectos: los primeros son aquellos en que la causalidad es del $100 \%$ y puede ser establecida a priori (por ejemplo: el costo en que incurre el país en el tratamiento de la drogodependencia); mientras que los segundos son aquellos donde esta imputación es parcial, requiriéndose de "fracciones etiológicas o atribuibles" debidamente fundamentadas que permitan cuantificar la magnitud del efecto del consumo de cada droga en conductas o situaciones adversas que generan costos. En Chile solo se cuenta con fracciones etiológicas estrictas para los costos indirectos de control o aplicación de la ley (law enforcement), es decir, el porcentaje de delitos que se cometen debido al uso y tráfico de drogas ilícitas y no solo bajo sus efectos. También en el ítem pérdidas de productividad existen estimaciones para calcular esta relación indirecta, ya sea como pérdidas de productividad por reclusión o por años de vida saludable, aunque en estos casos las estimaciones son menos precisas.

No obstante, no existen fracciones etiológicas que permitan cuantificar las consecuencias del consumo de drogas en enfermedades distintas a la drogodependencia y así determinar los costos que el consumo de drogas genera en el sistema de salud debido a enfermedades derivadas y parcialmente atribuibles. La ausencia de estimación para este ítem representa probablemente el principal defecto de la estimación que aquí se plantea. Asimismo, en este artículo se ha decidido excluir el daño a la propiedad representado por los costos producidos por accidentes de tránsito, dada la inexistencia de estudios de fracciones etiológicas al respecto. A diferencia de Olavarría (2009), se ha preferido aquí seguir siempre una opción conservadora en las estimaciones ${ }^{3}$.

\footnotetext{
${ }^{3}$ En el procedimiento de Olavarría se considera que todos los costos generados por accidentes de tránsito donde se detectó uso de alguna
}

Con relación al tercer y último paso, para la mayor parte de los ítems de este trabajo se cuenta con información de bastante calidad y estimaciones debidamente justificadas en aquellos casos en que no se dispone de antecedentes directos. Las fuentes y los métodos de asignación se explicitarán para cada ítem.

\section{Estructura de costos}

Los costos considerados han sido agrupados tanto en costos directos como indirectos a partir de cuatro ítems: i. Prevención: incluye campañas, dinero otorgado para investigación en drogas y todo el presupuesto del Consejo Nacional para el Control de Estupefacientes (CONACE) que no corresponde a estas áreas ni a tratamientos de rehabilitación ${ }^{4}$.

ii. Salud: tratamientos en el sistema público por consumo de drogas; se excluye al sistema privado y los costos indirectos por falta de información y de estudios sobre las fracciones etiológicas.

iii. Pérdidas de productividad: costo de oportunidad vinculado a los AVISA perdidos por mortalidad y morbilidad a causa de la drogodependencia, al riesgo que implica su consumo sobre otros males, y a la privación de libertad por delitos directa o indirectamente relacionados.

iv. Control: recursos empleados en la persecución de delitos e infracciones a la ley de drogas y de los delitos e infracciones cometidos a causa de la droga (véase el cuadro 1).

sustancia podían ser imputados a estas. Esto carece de fundamentos suficientes y exagera además la medición. Como muestran Longo y otros (2000a y 2000b), la tasa de responsabilidad en los accidentes de tránsito varía ampliamente según el tipo de drogas, pudiendo incluso invertirse para los conductores que registran menor concentración de tetrahidrocannabinol (THC) en la sangre.

4 En febrero de 2011 el conace fue refundado como Servicio Nacional para la Prevención y Rehabilitación del Consumo de Drogas y Alcohol (SENDA). 
CUADRO 1

\section{Estructura de costos}

\begin{tabular}{|c|c|c|}
\hline & Costos directos & Costos indirectos \\
\hline Prevención & $\begin{array}{l}\text { CONACE } \\
\text { Otras instituciones }\end{array}$ & - \\
\hline Salud (pública) & $\begin{array}{l}\text { Atención primaria y hospitalaria } \\
\text { Alianzas CONACE } \\
\text { Otras instituciones }\end{array}$ & (Sin fracciones etiológicas) \\
\hline Pérdidas de productividad & $\begin{array}{l}\text { Privación de libertad por ley de drogas } \\
\text { Mortalidad y morbilidad por dependencia }\end{array}$ & $\begin{array}{l}\text { Privación de libertad por delitos parcialmente atribuibles } \\
\text { Mortalidad y morbilidad parcialmente atribuibles al consumo de } \\
\text { drogas (droga como factor de riesgo) }\end{array}$ \\
\hline $\begin{array}{l}\text { Control } \\
\text { (Cada subítem para adultos } \\
\text { y menores, por separado) }\end{array}$ & $\begin{array}{l}\text { Infracciones a la ley de drogas: } \\
\text { Sistema policial } \\
\text { Sistema judicial } \\
\text { Sistema penal / SENAME } \\
\text { Otras instituciones }\end{array}$ & $\begin{array}{l}\text { Costos de control por delitos parcialmente atribuibles: } \\
\text { Sistema policial } \\
\text { Sistema judicial } \\
\text { Sistema penal / SENAME }\end{array}$ \\
\hline
\end{tabular}

Fuente: elaboración propia.

CONACE: Consejo Nacional para el Control de Estupefacientes.

SENAME: Servicio Nacional de Menores.

\section{III}

\section{Resultados}

\section{A. Resultados generales}

Como se denota en los cuadros 2 y 3 , la carga económica que representó para Chile el consumo de drogas en el año 2006 fue de al menos 266.744 millones de pesos corrientes de dicho año (lo que significaría 318.681 millones de pesos actuales, al 30 de abril de 2011). Esto equivale a más de 503 millones de dólares (de acuerdo con su valor nominal promedio en 2006), y representa el 0,45\% del PIB del país en tal año y un costo per cápita de 16.232 pesos o 31 dólares (véanse los cuadros 2 y 3 ).

La mayor parte de estos costos $(47 \%)$ se emplea en el control de delitos, sean contra la ley de drogas u otros delitos cometidos por su causa (para conseguirla, en el caso de los dependientes; bajo sus efectos, ya que el sujeto no habría delinquido sin estar bajo su influjo; o bien dentro del mercado de la droga). Le sigue la pérdida de productividad, que representa el $46 \%$ de los costos. Ambos ítems representan el $93 \%$ del total de los costos socioeconómicos de la droga en el país, aunque esta proporción se halla sobrestimada debido a la subestimación de los costos en salud, lo que incrementa el peso relativo del resto de los ítems. Los costos de prevención representan el 5\% del total, mientras que los de salud pública, el $2 \%$.

En el estudio para el año 2003 (CONACE, 2005), la distribución de los costos era muy distinta: también la mayor parte iba a control, con una proporción aún más alta que la presentada en este artículo, y le seguían de lejos los costos por pérdidas de productividad (23\%). El primer ítem fue notoriamente sobrestimado debido a que se imputaron los delitos al consumo de drogas por la mera presencia de esta en el detenido, sin contar con fracciones etiológicas; el segundo, en cambio, fue ampliamente subestimado por déficits en las fuentes de información utilizadas. En este artículo se corrige esta deficiencia al utilizar el estudio de la Escuela de Medicina (2008) de carga de enfermedad y carga atribuible para realizar una estimación precisa de la carga económica que representa para el país la drogodependencia y el consumo de drogas ilícitas.

El tercer ítem, salud pública, representaba el 16\% de los costos: su mayor magnitud obedece, por una parte, a la estimación sobre la base de fuentes secundarias que arrojaron resultados distintos de la información presupuestaria en que se funda la presente estimación $\mathrm{y}$, por otra, a la inclusión de costos indirectos sobre la 
Costos socioeconómicos del consumo de drogas en Chile: estimaciones totales y por ítem, 2003 y 2006

(En millones de pesos nominales, miles de dólares y porcentajes)

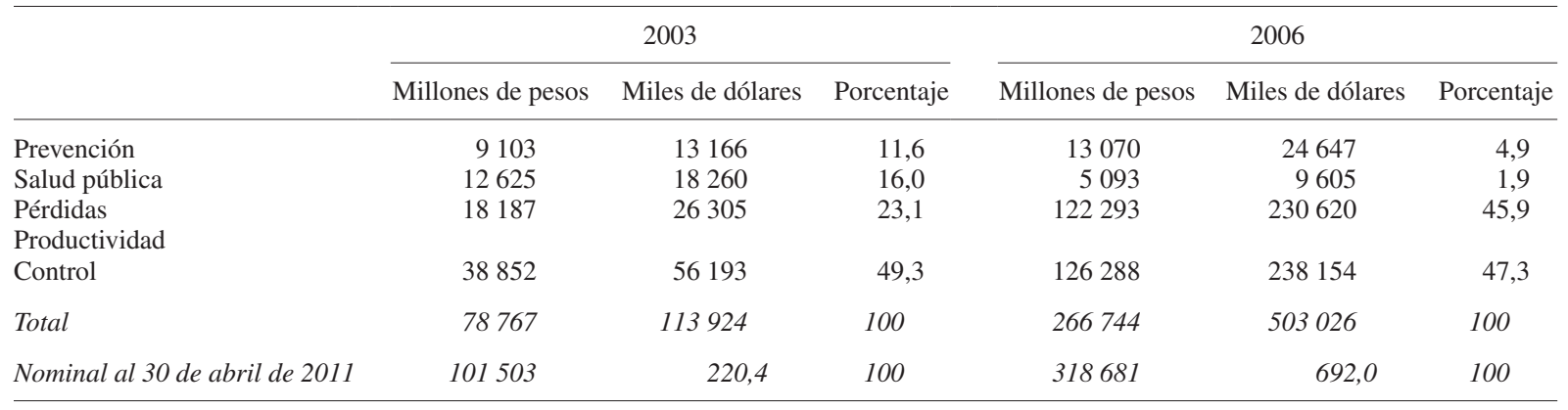

Fuente: elaboración propia sobre la base de datos para 2003 obtenidos del Consejo Nacional para el Control de Estupefacientes (CONACE), Estudio de costos asociados al consumo y tráfico de SPA ilegales en Chile para el año 2003, Santiago de Chile, 2005.

CUADRO 3

\section{Resultados globales de las estimaciones de costo socioeconómico del consumo de drogas, 2003 y 2006}

\begin{tabular}{lcc}
\hline & 2003 & 2006 \\
\hline Costo consumo drogas en millones & & \\
de pesos & 78767 & 266744 \\
Porcentaje del PIB & 0,15 & 0,45 \\
Costo per cápita en pesos & 4948 & 16233 \\
Dólares per cápita & 7,2 & 30,6 \\
\hline
\end{tabular}

Fuente: elaboración propia sobre la base de datos para 2003 obtenidos del Consejo Nacional para el Control de Estupefacientes (CONACE), Estudio de costos asociados al consumo y tráfico de SPA ilegales en Chile para el año 2003, Santiago de Chile, 2005.

PIB: producto interno bruto.

base del "Estudio de consumo de drogas en consultantes de los servicios de urgencia" (CONACE/CIGES, 2001); sin embargo, las fracciones atribuibles a drogas se estimaron como porcentaje del "total" de egresos por causas externas ingresadas en que se detectó presencia de drogas mediante test de orina, lo que implica nuevamente atribuir al uso de drogas el conjunto de los egresos donde son detectadas; por ejemplo, se les atribuyeron como causa única todos los accidentes en que se constató su presencia. Como se ha argumentado, este procedimiento es altamente cuestionable: si las drogas explican el $100 \%$ del accidente, se vuelve imposible explicar aquellos en los que no se detectó presencia de drogas. La inexistencia de un estudio que provea fracciones etiológicas confiables es el motivo por el cual en la presente estimación no se incluyen costos indirectos en el ítem de salud pública, aun cuando ello implica omitir un ítem de especial relevancia.

Finalmente, y en cuarto lugar, el ítem prevención representa el 11,6\% del total de los costos, un porcentaje mayor que el del estudio de 2006 que se explica por la menor cuantía de los costos totales, ya que la magnitud absoluta de este ítem se incrementó notoriamente (de 13,2 millones de dólares en 2003 a 24,7 millones de dólares en 2006). Dado que las fuentes de información y metodologías utilizadas difieren ampliamente, esta comparación es solo ilustrativa y no refleja cambios en la realidad.

\section{B. Estimaciones del costo socioeconómico del consumo de drogas, por ítem}

\section{Prevención}

En el cuadro 4 se pone de manifiesto que los costos de prevención durante el año 2006 alcanzaron a los 13.070 millones de pesos, provenientes prioritariamente del presupuesto del Consejo Nacional para el Control de Estupefacientes (CONACE). El actual Servicio Nacional para la Prevención y Rehabilitación del Consumo de Drogas y Alcohol (SENDA - ex CONACE- financia la mayor parte de las acciones de prevención del consumo de drogas en Chile, y su actividad prioritaria (anteriormente "Programa ConACE en su comuna: Previene"), "SENDA Previene", dispone de un aporte autónomo adicional de las distintas municipalidades para su implementación local. Se cuentan, además, las transferencias del CONACE a los gobiernos regionales y subregionales (intendencias y gobernaciones), así como —en investigación — al Programa de las Naciones Unidas para el Desarrollo 
(PNUD), al Servicio Nacional de Menores (SEnAme) y a otros organismos comunitarios, como fundaciones, iglesias o corporaciones privadas sin fines de lucro. El costo más importante —que está no obstante indirectamente vinculado a prevención - es "otros costos CONACE", que es la suma de todos aquellos costos del CONACE distintos de los previamente enumerados y de las transferencias para rehabilitación, incluidas en el ítem de costos en salud pública. Estos otros costos corresponden principalmente a los costos administrativos del CONACE a nivel nacional. Se los incluye en este ítem debido a que la prevención es el objeto último de esta institución, y en ausencia de consumo de drogas (escenario contrafactual), ella no existiría. Finalmente, la Policía de Investigaciones de Chile (PDI) realiza un aporte menor a través del Departamento de Educación Antinarcóticos y Seguridad Ciudadana para el desarrollo de talleres de prevención en el consumo de drogas.

\section{Salud pública}

En los estudios internacionales de cor respecto de drogas ilícitas, el ítem de salud representa usualmente una elevada fracción de los costos totales. En contraste, en este artículo se subestiman notoriamente los costos que genera el uso y abuso de drogas ilícitas en el sistema de salud. Además de no contar con costos indirectos — debido a la inexistencia en el país de un estudio de fracciones etiológicas para el consumo de drogas sobre enfermedades asociadas-, también los costos directos se encuentran subestimados debido a la ausencia de información sobre atenciones privadas de salud y tratamiento por drogodependencia.

Olavarría (2009) se ha arriesgado a realizar una estimación de costos privados en salud atribuibles a drogas. Este autor ha calculado el número total de tratamientos realizados en Chile empleando la base de datos expandida del estudio del CONACE en población general para el año 2006, asignándole a cada tratamiento el valor correspondiente al sistema público y restándole finalmente a este total el total conocido de los costos de los tratamientos financiados con fondos públicos. Así, supone que al restarle estos costos conocidos a los costos totales estimados mediante encuesta, obtiene el costo de los tratamientos en salud privada. Teóricamente este ejercicio es razonable, y dado que en él no se separan los costos por drogas y alcohol, muestra una estimación aparentemente plausible.

Sin embargo, siguiendo esta táctica pero separando los costos vinculados al consumo de drogas ilícitas de los relacionados con el alcohol, se alcanzan resultados sinsentido: se llega a tener costos negativos para determinados tipos de tratamientos; por ejemplo, hay casos en que se tienen más tratamientos en el sistema público (número conocido) que en el total estimado de tratamientos a partir de la encuesta (que correspondería, en la estrategia de Olavarría, al conjunto de tratamientos públicos y privados). Este resultado absurdo señala el

\begin{tabular}{llr}
\hline & CONACE en su comuna: “Previene” & 2681 \\
& Transferencias CONACE a intendencias & 2049 \\
& Transferencias de CONACE a gobernaciones & 96 \\
& Transferencias de CONACE a organismos comunitarios & 702 \\
Prevención CONACE & Transferencias de CONACE al PNUD & 21 \\
& Convenio CONACE - SENAME & 149 \\
& Transferencias de CONACE a otros organismos & 710 \\
& Otros costos CONACE (distintos de rehabilitación) & 5965 \\
\hline \multirow{2}{*}{ Prevención otras instituciones } & Talleres PDI & 14 \\
& Municipalidades (aportes autónomos a programas 'Previene') & 683 \\
Total & & 13070 \\
\hline
\end{tabular}

Fuente: elaboración propia sobre la base de información de M. Olavarría (2009), Estudio nacional sobre costos humanos, sociales y económicos de las drogas en Chile, 2006, Santiago de Chile, Olavarría y Asociados.

CONACE: Consejo Nacional para el Control de Estupefacientes. SENAME: Servicio Nacional de Menores. PNUD: Programa de las Naciones Unidas para el Desarrollo. PDI: Policía de Investigaciones de Chile. 
riesgo de generalizar expandiendo a nivel nacional un número de casos muy reducidos, y provee de una justificación contundente para excluir este ítem por falta de información.

En salud pública, Chile no cuenta con fuentes de información directa sobre los costos en atención primaria y hospitalaria atribuibles exclusivamente a drogas ilícitas; en el sistema de salud ambos tipos de atenciones —drogas ilícitas y alcohol- figuran en un solo ítem presupuestario. La distinción de costos vinculados a cada problema, sin embargo, puede ser estimada con relativa precisión sobre la base de la proporción díascama por hospitalizaciones debido a drogas y alcohol, según los registros del Departamento de Estadísticas e Información de Salud (DEIS) para 2006. En los cuadros 5 y 6 se entrega la información sobre la que se realiza este cálculo.

Si bien los egresos por alcohol representan el 75,5\% de los egresos totales, comprendidas ambas sustancias, la duración de la estadía por egresos atribuida a drogas es considerablemente mayor, con un promedio de 19,4 días por paciente, es decir, ampliamente superior a los 9,3 días promedio de estadía de los casos atribuidos

CUADRO 5

Egresos hospitalarios y días-cama por alcohol y drogas, 2006

\begin{tabular}{lcc}
\hline & Alcohol & Drogas \\
\hline Egresos asociados & 7530 & 2447 \\
Total días-cama & 69683 & 47441 \\
Promedio días-cama & 9,3 & 19,4 \\
Porcentaje del total de egresos & 0,5 & 0,1 \\
Porcentaje del total de días-cama & 0,77 & 0,52 \\
\hline
\end{tabular}

Fuente: elaboración propia sobre la base de datos de egresos hospitalarios del Departamento de Estadísticas e Información de Salud (DEIS) del Ministerio de Salud de Chile.

CUADRO 6

Porcentaje de egresos y días-cama por alcohol y drogas sobre el total alcohol + drogas, 2006

Egresos drogas de los egresos por alcohol y drogas 24,5 Egresos alcohol de los egresos por alcohol y drogas Días-cama por droga de los días por alcohol y drogas

Fuente: elaboración propia sobre la base de datos de egresos hospitalarios del Departamento de Estadísticas e Información de Salud (DEIS) del Ministerio de Salud de Chile. a alcohol. Con esto, el sistema público cubrió 69.683 días-cama por alcohol y 47.441 por drogas ilícitas. Con respecto a estos últimos valores se estiman los costos: los días-cama por droga representan el 40,5\% del total de días-cama debidos a alcohol y drogas, y con ello, el mismo porcentaje de los recursos destinados a ambos ítems. Así, se ha considerado que el 40,5\% de los recursos destinados a alcohol y drogas en atenciones hospitalarias corresponde a drogas, y el 59,5\% a alcohol. Dado que se sabe por planilla presupuestaria que el total de los recursos asignados al tratamiento de alcohol y drogas en la atención hospitalaria fue de 1.062 millones de pesos, el 40,5\% de tal monto, es decir, 430,4 millones de pesos corresponde a drogas.

Por otra parte, debido a que no se cuenta con registros de egresos para el caso de atención primaria y hospitales psiquiátricos, se ha supuesto que los recursos destinados a alcohol y drogas se distribuyen en proporciones semejantes al sistema hospitalario. Sobre la base de las estimaciones de Olavarría (2009), se considera que los costos por alcohol y drogas alcanzan a 2.195 millones de pesos; consecuentemente, el 40,5\% u 889 millones corresponderían a drogas.

Además, tanto en la estimación para 2003 (CONACE, 2005), como en la de Olavarría (2009) para alcohol y drogas en 2006, se considera el gasto de organizaciones no gubernamentales (ONG) en tratamientos; en la primera, sin embargo, solo se incluyó una organización, mientras que en la segunda se incluyeron los montos de aquellas que decidieron responder a la solicitud de información enviada (nueve en total), todas ellas en la Región Metropolitana. Debido a la falta de sistematicidad de esta recolección de información, en el presente artículo se ha excluido el gasto que las ONG realizan en tratamiento, en el entendido de que un estudio de costos debe basarse en un modelo estable y replicable en el tiempo; la selección aleatoria de estas instituciones hace imposible su consideración para un estudio sistemático y comparable. A objeto de subsanar este problema se requeriría un catastro exhaustivo de las ONG dedicadas a la rehabilitación por consumo de drogas que otorguen información de calidad.

Los costos de tratamientos de rehabilitación y desintoxicación en cárceles y centros del SENAME, en cambio, se encuentran bien documentados y corresponden, probablemente debido a esto, al principal subítem de los costos de salud pública. Cabe suponer que los costos de los tratamientos en centros privados son de una magnitud considerable, pero no existe información al respecto (véase el cuadro 7). 
CUADRO 7

Costos en salud pública por consumo y abuso de drogas, 2006

(En millones de pesos nominales)

\begin{tabular}{llr}
\hline & Subítem & Millones de pesos \\
\hline Atención primaria y hospitalaria & Tratamientos por sustancias psicoactivas en atención primaria & 430 \\
& Atención en hospitales generales y psiquiátricos & 889 \\
Alianzas CONACE & Convenio FONASA - CONACE & 3521 \\
& Convenio CONACE - GENCHI & 232 \\
Otras instituciones & Aportes de GENCHI & 20 \\
Total & & 5093 \\
\hline
\end{tabular}

Fuente: elaboración propia sobre la base de M. Olavarría, 2009, Estudio nacional sobre costos humanos, sociales y económicos de las drogas en Chile, 2006, Santiago de Chile, Olavarría y Asociados, y de la base de datos del Departamento de Estadísticas e Información de Salud (DEIS) del Ministerio de Salud de Chile.

CONACE: Consejo Nacional para el Control de Estupefacientes.

FONASA: Fondo Nacional de Salud.

Genchi: Gendarmería de Chile.

\section{Pérdidas de productividad}

Los costos por pérdidas de productividad suelen representar el ítem de mayor relevancia en las estimaciones de costos socioeconómicos ocasionados por la droga. En los Estados Unidos de América, por ejemplo, representan en el año 2002 el 71,2\% del total de los costos socioeconómicos atribuidos al abuso de drogas (Oficina Nacional de Fiscalización de Drogas, 2004). La presente estimación de costos opera inicialmente con dos distinciones en este ítem: i) costos por AVISA perdidos por enfermedad o muerte prematura, así como costos por años de vida perdidos por privación $<$ de libertad, y ii) costos directos e indirectos.

\section{a) Pérdidas de productividad por privación de libertad: costos directos e indirectos}

Los costos por privación de libertad debido a infracciones a la ley de drogas se obtienen del producto entre el número promedio de reclusos por infracciones o delitos contra la ley de drogas, el salario mínimo - que fue de $\$ 131.250$ en 2006- y un período de 12 meses. El supuesto en este caso es que el salario mínimo es un costo alternativo más realista para la población recluida ${ }^{5}$ que el ingreso medio poblacional.

\footnotetext{
5 Olavarría (2009) usa otra fuente y considera solo a los condenados. Aquí se usa la cifra del total de reclusos, pues también los imputados, detenidos y procesados por delitos de drogas representan un costo directamente vinculado al consumo de drogas.
}

El cálculo de los costos por privación de libertad por delitos parcialmente atribuibles a drogas representa una dificultad algo mayor. En primer lugar, no existe en Chile información exacta sobre la cantidad de internos promedio en las cárceles por cada tipo de delito. La única información disponible es la distribución de delitos entre la población recluida. Sobre la base de dicha información, una buena estimación puede obtenerse al homologar la proporción existente en el caso de la ley de drogas, que es la única disponible. Del promedio de personas en sistema cerrado, 3.468 de un total de 38.007 se encontraban privadas de libertad por infracción a la ley de drogas, lo que corresponde al 9,13\% de las personas recluidas en 2006. Al contrastar esta información con la disponible sobre delitos de los recluidos, vemos que 12.487 delitos de un total de 139.333 corresponden a drogas, lo que equivale a un $8,96 \%$. Si se considera que ambos porcentajes son prácticamente idénticos, para el cálculo del número promedio anual de internos recluidos por hechos delictuales relacionados con drogas, se supone que su porcentaje —estimado a partir del "total" de los "delitos de los recluidos registrados en el sistema de internos"- es igual al porcentaje de los reclusos "promedio" por año para las mismas infracciones. Aquí siempre se utiliza el período de 12 meses, dado que la estimación del promedio anual de reclusos con respecto a los distintos delitos es efectuada con precisión, y se puede asignar un costo alternativo de productividad para

\footnotetext{
6 Delitos y no personas: muchas se encuentran recluidas por más de un delito.
} 
cada uno de los 12 meses. Se desconoce, en cambio, la duración específica de la reclusión de cada una de las personas para los distintos tipos de delitos y motivos de reclusión (detenidos, condenados o procesados). Los resultados de esta estimación figuran en la columna "reclusos promedio 2006" del cuadro 8.

En segundo lugar, la estimación de pérdidas de productividad por delitos imputables al uso, abuso y tráfico de drogas que no son, sin embargo, tipificados como delitos contra la ley de drogas, requiere una estimación de fracciones etiológicas o atribuibles a estas, que en Chile han sido recientemente desarrolladas por Valenzuela y Larroulet (2010). En epidemiología una fracción etiológica o atribuible es una forma indirecta de cuantificar la morbosidad y mortalidad debido a un factor de riesgo específico (is a form of indirect quantification of morbidity and mortality due to a specified risk factor) (Ridolfo y Stevenson, 2001, pág. 2). En este caso, la fracción corresponde al porcentaje de los distintos tipos de delitos que pueden ser atribuidos al consumo y dependencia de distintas drogas.

Valenzuela y Larroulet (2010) utilizan el modelo tripartito de Goldstein (1985) para evaluar este vínculo. Según este modelo, la incidencia del consumo de drogas en la comisión del delito tiene lugar bajo tres escenarios:

i. Se habla de una conexión "psicofarmacológica" para describir aquellos delitos que se cometen bajo la influencia de sustancias que incrementan la excitabilidad, la irracionalidad o disposiciones violentas, y se incluyen los casos en que la víctima se encuentra bajo los efectos de alguna sustancia, en el entendido de que la vulnerabilidad de la víctima puede constituir una oportunidad para cometer el delito.

ii. Se habla de una conexión "económica compulsiva" en aquellos casos en que el drogodependiente delinque con el objeto de proveerse de drogas o de los medios necesarios para obtenerlas; finalmente,

iii. Existe una conexión "sistémica" en aquellos delitos que resultan de la operación de las redes de producción e intercambio de drogas. Sobre esta conceptualización se estiman fracciones etiológicas para cada tipo de delito y de conexión, sobre la base de los estudios del SENAME en población infractora (SENAME, 2006) y del CONACE en población penal adulta de 2007 (CONACE, 2007).

Por último, para el factor de ingresos se optó por el salario mínimo en desmedro del ingreso medio, bajo el supuesto de que el primero representa un costo alternativo más realista para el caso de la población recluida (véase el cuadro 8).

Pérdidas de productividad por mortalidad y morbilidad atribuible a drogas: años de vida saludable (AVISA) perdidos.

\section{- Estudio de carga de enfermedad y carga atribuible en Chile}

Las pérdidas por mortalidad y morbilidad son un ítem de especial relevancia en los estudios internacionales. Chile cuenta con el Estudio de carga de enfermedad y carga atribuible desarrollado por el Departamento de

Costos en pérdidas de productividad por privación de libertad: costos directos (ley de drogas) e indirectos (delitos relacionados), 2006

\begin{tabular}{|c|c|c|c|c|c|}
\hline & & $\begin{array}{l}\text { Reclusos } \\
\text { promedio } \\
2006^{\mathrm{a}}\end{array}$ & $\begin{array}{l}\text { Fracción } \\
\text { atribuible }\end{array}$ & $\begin{array}{l}\text { Sueldo } \\
\text { mínimo }^{c} \\
\text { en pesos }\end{array}$ & $\begin{array}{l}\text { Costo en } \\
\text { millones } \\
\text { de pesos }\end{array}$ \\
\hline Privación de libertad por ley de drogas (costo directo) & & 3468 & 1 & 131250 & 5462 \\
\hline Privación de libertad por delitos asociados (costo indirecto) & $\begin{array}{l}\text { Robo simple } \\
\text { Robo con violencia } \\
\text { Delito sexual } \\
\text { Homicidio }\end{array}$ & $\begin{array}{r}14601 \\
7906 \\
1447 \\
1939\end{array}$ & $\begin{array}{l}0,327 \\
0,287 \\
0,079 \\
0,206\end{array}$ & $\begin{array}{l}131250 \\
131250 \\
131250 \\
131250\end{array}$ & $\begin{array}{r}7520 \\
3574 \\
180 \\
629\end{array}$ \\
\hline Total & & & & & 17365 \\
\hline
\end{tabular}

Fuente: elaboración propia sobre la base de:

a Ministerio de Justicia, Compendio estadístico de la población atendida por Gendarmería de Chile, Santiago de Chile, Gendarmería de Chile, Sub Departamento de Estadística y Control Penitenciario, 2006.

b E. Valenzuela y P. Larroulet, "La relación droga y delito: una estimación de la fracción atribuible", Estudios públicos, N 119, Santiago de Chile, Centro de Estudios Públicos (CEP), 2010.

c Ley 20.039 que reajusta el ingreso mínimo mensual. 
Salud Pública de la Escuela de Medicina de la Pontificia Universidad Católica de Chile (Escuela de Medicina, 2008), en que se estiman los años de vida saludable (AVISA) perdidos como "carga de enfermedad", esto es, que tienen como causa específica una enfermedad; y los AVISA perdidos como carga atribuible a determinados comportamientos (17 factores de riesgo) respecto de otras enfermedades distintas de la específica.

Los AVISA para una "causa específica" corresponden a la suma de los años de vida perdidos debido a muerte prematura por la causa específica, más los años de vida vividos con discapacidad para los casos incidentes de la causa específica. La cantidad de AVISA perdidos que tienen como causa específica la dependencia de drogas otorga una medida para evaluar el efecto "directo" del consumo de drogas en la reducción futura de la salud, siendo clave para la estimación consecuente del costo de oportunidad por mortalidad y morbilidad atribuibles directamente a drogas.

Los AVISA atribuibles al consumo de drogas, como estimación de costos indirectos, se obtienen de una estimación de carga atribuible en que se evalúa la incidencia de 17 "factores de riesgo" en el daño final (medidos en AVISA perdidos). "La carga atribuible es la reducción en la carga actual que se observaría si los niveles de exposición en el pasado hubiesen sido similares a una determinada distribución hipotética" (Escuela de Medicina, 2008, pág. 79). El factor de riesgo de interés en este caso es el "uso de drogas ilícitas", que representa por lejos el factor de riesgo menos significativo de los 17 factores considerados (0,0\% del total, Escuela de Medicina, 2008). En el estudio se considera el consumo de drogas como factor de riesgo de suicidio, violencias y accidentes de tránsito. La carga atribuible a este factor es de 417 AVISA. Hay fundadas razones para suponer que en dicha cifra se subestima la magnitud real, principalmente debido a que en su cálculo se usan las prevalencias reportadas por el estudio del CONACE en población general, que se basó en preguntas de autorreporte ${ }^{7}$ en las que, debido a ello, se subestima la magnitud del fenómeno y se marginan las enfermedades que, pese a estar demostrado que se vinculan al consumo de drogas, no cuentan con fracciones etiológicas por drogas en Chile.

La carga económica por pérdida de productividad debida a AVISA perdidos permite evaluar en valor presente el ingreso potencial futuro. Dado que las personas valoran más los beneficios actuales que los futuros, se requiere aplicar una tasa de descuento que influye sensiblemente

\footnotetext{
7 Declaración de un encuestado sobre sí mismo, por ejemplo, si ha consumido drogas en los últimos 30 días.
}

en el monto descontado final. En general, mientras más incierto el futuro, más alto es el valor que las personas le asignan al presente (the more uncertain the future, the higher the value individuals give to the present) (Kopp, 2001, pág. 19). La selección de una determinada tasa no se encuentra consensuada (Single y otros, 2003; Kopp, 2001) y, en general, "refleja parcialmente la opinión del investigador sobre el grado de dificultad que impondrá la sociedad para vivir como drogadicto [...] mientras más baja la tasa seleccionada más alto el costo social estimado" (partly reflects the researcher's opinion about how difficult a society will make it to live as a drug user. [...] The lower the selected rate the higher the estimated social cost) (Kopp, 2001, pág. 19). Usualmente se sugiere una tasa entre el $5 \%$ y el $10 \%$, sin embargo, una tasa de descuento del $3 \%$ es la más común (a 3 percent discount rate is most common) (Segel, 2006, pág. 30).

En el estudio de la Escuela de Medicina de la Pontificia Universidad Católica de Chile se utiliza una tasa de descuento de un 3\%, que según se señala en el estudio, "corresponde al crecimiento de la inversión en el largo plazo, y es utilizada ampliamente en estudios de evaluación de proyectos sociales" (Escuela de Medicina, 2008, pág. 33). Esta tasa es relativamente baja y tiene como consecuencia que los costos derivados podrían encontrarse ligeramente sobrestimados.

Finalmente, el cálculo de los AVISA respecto de la esperanza de vida para las distintas cohortes, y no respecto de la vida económicamente activa, podría representar un problema para una estimación de costos en que se asigna un valor a los ingresos no recibidos por la producción no realizada en la vida laboral. Esta dificultad se soluciona mediante la incorporación de un factor de valoración del tiempo vivido en cada edad (Escuela de Medicina, 2008, pág. 32), donde se le otorga un mayor peso a los grupos más jóvenes.

\section{- Procedimientos en la estimación de costos por mortalidad y morbilidad atribuibles a drogas (directos e indirectos)}

La primera decisión relevante para estimar los costos de este ítem es el monto que se asigna a cada AVISA perdido. A diferencia de las pérdidas de productividad por reclusión, en este caso se opta por el ingreso medio y no por el salario mínimo, ya en que el estudio de consumo de drogas en población general de Chile realizado en 2006 se aprecia que el ingreso promedio declarado por los drogodependientes no difiere significativamente del declarado por el resto de la población (y las diferencias, además de bajas, son favorables a los dependientes). El 
ingreso autónomo diario promedio se obtiene a partir de la Encuesta de Caracterización Socioeconómica Nacional (CASEN) de 2006. Los costos directos de pérdidas de productividad resultan del producto entre los AVISA perdidos por dependencia de drogas como causa específica, el ingreso autónomo diario (11.114 millones de pesos en 2006), y 365 (días del año). De este cálculo se obtiene que la carga económica que representan para Chile las pérdidas de productividad por mortalidad y morbilidad directamente atribuibles a la dependencia de drogas alcanzó a los 103.000 millones de pesos en 2006.

El mismo procedimiento se ha usado para los AVISA perdidos a causa del consumo de drogas por enfermedades distintas de la drogodependencia (costo indirecto). Dado que los AVISA perdidos por consumo de drogas como factor de riesgo se encuentran subestimados, también lo está el monto resultante del producto de los factores incorporados. La carga económica de los AVISA perdidos a causa del consumo de drogas como factor de riesgo de enfermedades distintas de la drogodependencia alcanzaría a los 1.907 millones de pesos, en moneda corriente del año 2006. En su conjunto, la carga económica por mortalidad y morbilidad directa e indirectamente atribuible a drogas ilícitas habría alcanzado aproximadamente a los 105.000 millones de pesos (véase el cuadro 9).

\section{Control}

Los costos de control atribuibles a drogas - correspondientes al ítem usualmente denominado "aplicación de la ley"- representan la proporción más importante de los costos estimados en este artículo (46,6\%). Usualmente, en cambio, son los costos por pérdidas de productividad los que ocupan el primer lugar (aquí representan el 45,1\%). Las razones que explican esta diferencia son principalmente dos: Chile cuenta con información muy sólida para la realización de los cálculos en este ítem (especialmente en adultos) y con un estudio de fracciones atribuibles de buen nivel para el cálculo de los costos indirectos, lo que ha dado lugar a una estimación exhaustiva. En contraste, las fracciones etiológicas por pérdidas de productividad por años de vida saludable perdidos (AvisA perdidos como factor de riesgo) se encuentran subestimadas.

En el cálculo de los costos que una institución destina al control de los delitos directa o indirectamente vinculados a la droga, por lo general se define una actividad relevante e idealmente equivalente, para luego estimar la proporción de actividades vinculadas a drogas sobre el total de actividades de la institución. Este supuesto implica asumir que los recursos destinados a las distintas actividades son iguales, un supuesto ampliamente utilizado (Pacula y otros, 2009, pág. 34), pero muy poco plausible: la indagación de un homicidio moviliza una cantidad de recursos distinta a la de un hurto. Con el objetivo de otorgar un peso desigual a los distintos delitos, se ha calculado una variable sustitutiva (proxy) de dificultad relativa de investigación de los distintos delitos sobre la base de la duración de los procesos judiciales relacionados con cada uno de ellos. Como variable sustitutiva, esta no refleja exacta ni proporcionalmente la dificultad del delito asociado, pues existe una base de tiempo burocrático común a todo delito y siempre es posible que en algunos de ellos sea preponderante recurrir a salidas alternativas abreviadas o a una persecución intensificada por la fiscalía.

A partir de la estandarización de los tiempos promedio de duración de los procesos para cada tipo de

CUADRO 9

Costos directos e indirectos por pérdidas de productividad debido a morbilidad y mortalidad prematura atribuibles a drogas, 2006

\begin{tabular}{|c|c|c|c|}
\hline & AVISA $^{\mathrm{a}}$ & $\begin{array}{l}\text { Ingreso autónomo diario } \\
\text { promedio }^{\mathrm{b}} \text { en pesos }\end{array}$ & $\begin{array}{c}\text { Costo en millones } \\
\text { de pesos }\end{array}$ \\
\hline AVISA perdidos por dependencia de drogas, como causa específica & 25396 & 11114 & 103022 \\
\hline AVISA perdidos por uso de drogas ilícitas, como carga atribuible (factor de riesgo) & 470 & 11114 & 1907 \\
\hline Total & & & 104929 \\
\hline
\end{tabular}

Fuente: elaboración propia sobre la base de:

a Escuela de Medicina, Estudio de carga de enfermedad y carga atribuible 2007, Santiago de Chile, Departamento de Salud Pública, Pontificia Universidad Católica de Chile, 2008, y

b Encuesta de Caracterización Socioeconómica Nacional (CASEN), 2006. AVISA: años de vida saludable. 
delito, se calcula un factor ponderador. Si este factor es menor de 1 significa que su duración (y su dificultad) es menor que la media, y lo mismo en sentido inverso. En el cuadro 10 se muestran los valores de los ponderadores para los delitos de interés.

Los delitos asociados por Valenzuela y Larroulet (2010) son "homicidios", "delitos sexuales", "robo con violencia" y "robo simple", que incluye toda clase de robos no violentos y hurtos. Para estimar la dificultad relativa de los delitos de robo simple se calcula el promedio ponderado (por frecuencia) de "robos no violentos" ( $\mathrm{n}=193.517)$ y "hurtos" $(\mathrm{n}=133.303)$, lo que arroja 87,16 días, implicando un ponderador de 0,828 .

Con este factor incorporado se estimaron los costos que para cada institución representa la persecución de delitos e infracciones a la ley de drogas y delitos asociados. El costo nominal de este ítem superó los 126.000 millones de pesos en 2006. El
37,3\% corresponde a costos directos (persecución, juicio y encarcelamiento de los delitos contra la ley 20.000 de control de drogas y estupefacientes), mientras que el $62,7 \%$ restante se refiere a delitos de otra naturaleza cuya comisión se debe, sin embargo, al consumo, abuso y tráfico de drogas (esta última opción es menos frecuente: se trata de delitos, como un robo u homicidio, que se cometen en el tráfico de sustancias). Esto significa que Chile perdió más de 47.000 millones de pesos en 2006 por persecución de delitos de drogas, y casi 80.000 millones de pesos en control de otra clase de delitos imputables al consumo y tráfico de sustancias. La mayor parte de estos costos los asume el sistema policial $(42,6 \%)$, seguido del sistema penitenciario $(37,1 \%)$ y el judicial $(19 \%)$. Otras instituciones menores asumen el 1,3\% restante de los costos en control: Servicio Médico Legal, Unidad de Análisis Financiero, Servicio Nacional de Aduanas y Dirección General

Duración de los procesos judiciales y estimación

de dificultad relativa (ponderador) de los delitos, 2006

\begin{tabular}{lccr}
\hline & Tiempo tramitación (días) & Valor estandarizado & Factor ponderador \\
\hline Robos & 118 & 124,2 & 1,242 \\
Robos no violentos & 99 & 104,2 & 1,042 \\
Hurtos & 70 & 73,7 & 0,737 \\
Homicidios & 297 & 312,6 & 3,126 \\
Delitos sexuales & 234 & 246,3 & 2,463 \\
Delitos ley de drogas & 177 & 186,3 & 1,863 \\
Promedio general & 95 & 100 & 1,000 \\
\hline
\end{tabular}

Fuente: elaboración propia sobre la base de información disponible en Ministerio Público, Boletín estadístico. Año 2006, Santiago de Chile, Fiscalía Nacional.

CUADRO 11

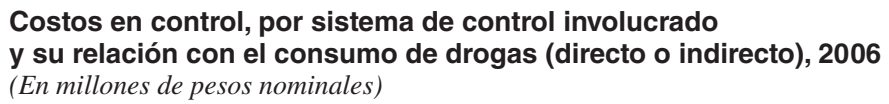

\begin{tabular}{lcccc}
\hline & Directos & Indirectos & Total & Porcentaje \\
\hline Sistema policial & 22155 & 31650 & 53805 & 42,6 \\
Sistema judicial & 8248 & 15797 & 24045 & 19,0 \\
Sistema penitenciario y de rehabilitación (SENAME) & 15035 & 31780 & 46815 & 37,1 \\
Otros & 1624 & - & 1624 & 1,3 \\
Total & 47062 & 79227 & 126288 & 100 \\
(Porcentaje) & $(37,3)$ & $(62,7)$ & $(100)$ & \\
\hline
\end{tabular}

Fuente: elaboración propia.

SENAME: Servicio Nacional de Menores. 
del Territorio Marítimo y de Marina Mercante (DIRECTEMAR $^{8}$ ) (véase el cuadro 11 ).

A su vez, el $14,7 \%$ de estos costos se debe a la persecución e internación de menores infractores por delitos contra la ley de drogas y por la comisión de otros delitos asociados (18.541 millones de pesos), mientras que el $85,3 \%$ se gasta en la persecución de los mismos delitos en población adulta (107.747 millones de pesos) (véase el cuadro 12).

\section{a) Costos directos en control: adultos}

En adultos, las instituciones relevantes en el control de los delitos de drogas y asociados son Carabineros de Chile y la PDI (sistema policial), el Poder Judicial, el Ministerio Público de Chile y la Defensoría Penal Pública (sistema judicial), la Gendarmería de Chile (que junto con los costos de construcción de cárceles dan lugar al sistema penal) y otras instituciones menores. En su conjunto, la carga económica que representó para estas instituciones la persecución a infracciones a la ley de drogas supera los 40.000 millones de pesos.

- Carabineros de Chile efectuó 448.128 detenciones o aprehensiones (INE, 2008b). De ellas, 9.870 fueron detenciones por infracción a la ley de drogas. El ponderador de dificultad relativa para los delitos de drogas es de 1,863. El producto obtenido del porcentaje de actividades relacionadas, dicho ponderador y el presupuesto institucional muestran

${ }^{8}$ Información obtenida del estudio de Olavarría (2009).

CUADRO 12

Costos en control, por sistema de control involucrado y su persecución en el tráfico y consumo en menores y adultos, 2006 (En millones de pesos nominales)

\begin{tabular}{lccr}
\hline & Menores & Adultos & Total \\
\hline Sistema policial & 7427 & 46377 & 53805 \\
Sistema judicial & 199 & 23846 & 24045 \\
Sistema penitenciario y de & & & \\
rehabilitación (SENAME) & 10916 & 35900 & 46815 \\
Otros & - & 1624 & 1624 \\
Total & 18541 & 107747 & 126288 \\
(Porcentaje) & $(14,7)$ & $(85,3)$ & $(100)$ \\
\hline
\end{tabular}

Fuente: elaboración propia.

SENAME: Servicio Nacional de Menores. que en 2006 Carabineros destinó 13.169 millones de pesos a la persecución de delitos de drogas.

- La PDI realizó en 2006 un total de 179.955 investigaciones, de las que 6.468 corresponden a drogas (INE, 2008a, pág. 101). La proporción de investigaciones de delitos de drogas sobre el total de investigaciones, multiplicada por el ponderador y el presupuesto institucional, permite estimar que durante 2006 la PDI destinó 5.790 millones de pesos a la investigación de delitos de drogas.

- En 2006 ingresaron al Ministerio Público 1.013.833 delitos, de los cuales 11.323 correspondieron a infracciones a la ley de drogas. De acuerdo con el mismo modo de cálculo empleado en los casos previos, se obtiene que el Ministerio Público destinó 1.620 millones de pesos a la investigación de delitos por infracción a la ley de drogas.

- A la Defensoría Penal Pública ingresaron durante 2006 un total de 212.095 delitos, de los cuales 8.741 se debieron a infracciones a la ley de drogas. Así, esta Defensoría destinó 2.281 millones de pesos a la defensa de imputados por esta clase de delitos.

- Bajo el título de Poder Judicial se incluye tanto al Poder Judicial como a la Corporación Administrativa del Poder Judicial (CAPJ) y la Academia Judicial. La información de delitos para el cálculo de costos ha sido tomada del estudio de Olavarría (2009), quien a su vez la elaboró con datos obtenidos mediante oficio por parte de la CAPJ; los delitos de drogas alcanzaron a 25.764 de un total de 2.193.142 ingresados al Poder Judicial; el costo vinculado a los delitos por infracción a la ley de drogas alcanza a los 4.253 millones de pesos.

- Gendarmería de Chile, por su parte, registró durante 2006 un promedio de 3.468 personas recluidas por delitos contra la ley de drogas, sobre un total de 38.007 personas recluidas promedio durante el mismo año. Esto corresponde al 9,13\% de los delitos de los recluidos; se estima que este porcentaje corresponde a la proporción de recursos destinados al encarcelamiento por delitos de drogas, marginándose aquí el ponderador, ya que para Gendarmería el encarcelamiento por distintos delitos no representa esfuerzos ni recursos desiguales. Con esto, durante 2006 Gendarmería gastó 11.152 millones de pesos en la reclusión por infracciones a la ley de drogas.

- A lo anterior corresponde agregar el costo de construcción de cárceles. De acuerdo con el estudio de Olavarría (2009), el costo anual de construcción de cárceles debe medirse según su depreciación anual. 
Olavarría, asume que la vida útil de las cárceles es de 50 años, de manera que "el valor total por el costo de construcción de cárceles asignable al año 2006 sería un cincuentavo de la suma actualizada al 2006 del valor de construcción de los penales en operación a ese año" (Olavarría, 2009, pág. 65). De la multiplicación de su depreciación anual y la proporción de personas recluidas por infracciones a la ley de drogas, se tiene que Chile gastó 349 millones de pesos en la construcción de cárceles para la reclusión de personas que infringieron dicha ley. Esta cifra no coincide con la presentada en el estudio recién mencionado, ya que en aquel se consideran los delitos por droga y alcohol y además solo los condenados, mientras que en el presente se incluyen los condenados, procesados e imputados por delitos de drogas — no de alcohol—, puesto que todos ellos están igualmente recluidos en las instituciones de Gendarmería. Las estimaciones corresponden, como siempre, al promedio anual de reclusos por delito y no al total de personas atendidas por Gendarmería.

- Los costos atribuibles a drogas por parte del Servicio Médico Legal se estiman como el porcentaje del gasto que los exámenes toxicológicos representan para el total de exámenes de laboratorio (15\%), que a su vez representan el $61 \%$ del gasto del Servicio Médico Legal. Con esto se tiene que esta institución gastó 989 millones de pesos en exámenes de drogas en 2006.

- Para el caso de la Unidad de Análisis Financiero del Ministerio de Hacienda, que investiga delitos de lavado de dinero, no existe información sobre el porcentaje de Reportes de Operaciones Sospechosas vinculadas a drogas. Se asumió por tanto que estos delitos se distribuyen del mismo modo que en el Ministerio Público, con lo que se tiene que esta institución gasta 132 millones de pesos anuales en la investigación de delitos de lavado de dinero vinculados a drogas.

- El Servicio Nacional de Aduanas gastó 344 millones de pesos en el control de drogas en 2006; cifra que corresponde al presupuesto del Departamento de Fiscalización de Drogas de esa institución.

- La Dirección General del Territorio Marítimo y Marina Mercante (DIRECTEMAR) desarrolla distintas actividades de control y combate del tráfico de estupefacientes; de acuerdo con la información proporcionada a Olavarría (2009), estas corresponden al $0,48 \%$ del total de actividades realizadas por la institución, con lo que se tiene que esta entidad gastó, en 2006, 157 millones de pesos en el ítem mencionado (véase el cuadro 13).

\section{b) Costos directos en control: menores}

En menores, se estima que durante 2006 entre Carabineros de Chile, el Poder Judicial y el SENAme gastaron 6.822 millones de pesos en el control de delitos de drogas. No obstante, la información para menores es imprecisa, ya que antes de la entrada en vigencia de la ley de responsabilidad penal juvenil (RPJ) no existían sistemas de información adecuados exclusivos para menores infractores.

- No existe información exacta sobre el número de menores infractores detenidos por delitos vinculados a drogas durante 2006; se sabe, sin embargo, que dicho año Carabineros de Chile detuvo a 25.952 menores y se conoce, además, la caracterización de los menores que ingresaron al Programa 24 horas $^{9}$ entre 2001 y 2005 por infracciones a la ley. Para estimar el número de delitos en 2006, se supone que ese año las detenciones se distribuyeron por delitos, del mismo modo que entre los años 2001-2005. Se deduce así que en 2006 se detuvo a 2.396 menores por consumo de drogas (el único delito vinculado a drogas categorizado), lo que corresponde al 0,53\% del total de las detenciones realizadas ese año. Incorporando el ponderador presentado, se tiene que en 2006 carabineros gastó 3.196 millones de pesos en la detención de menores por consumo de drogas (véase el cuadro 14).

- En el campo de la justicia existe un gran vacío de información sobre menores infractores antes de la entrada en vigencia de la ley de RPJ en 2007. No hay registros de la fiscalía para juicios de menores que hubiesen cometido el delito entre los $14 \mathrm{y}$ 17 años y fuesen declarados con discernimiento, porque en tal caso eran juzgados como adultos. Tampoco se cuenta con información con respecto a la defensa. Debido a esto no es posible estimar costos para estas instituciones, y solo puede realizarse una estimación muy gruesa para el Poder Judicial. Ya que se desconoce el número de delitos de drogas (y de todo el resto) ingresados en 2006,

\footnotetext{
${ }^{9}$ Formalmente, "Programa de Seguridad Integrada para Niños, Niñas y Adolescentes 24 horas", cuyo objetivo es recopilar información sobre niños, niñas y adolescentes que ingresan al sistema policial y contactarlos con la red de atención y protección social que se organiza en torno a los municipios con el fin de prevenir tempranamente la delincuencia (Allende y Valenzuela, 2008).
} 
Costos en control directamente atribuibles al tráfico y consumo de drogas, adultos, 2006

(En millones de pesos nominales)

\begin{tabular}{|c|c|c|c|c|c|c|c|}
\hline & & $\begin{array}{l}\text { Presupuesto } \\
\text { total (millones } \\
\text { de pesos) }\end{array}$ & $\begin{array}{l}\text { Actividades } \\
\text { relacionadas } \\
\text { (número) }\end{array}$ & $\begin{array}{l}\text { Total de } \\
\text { actividades }^{b} \\
\text { (número) }\end{array}$ & $\begin{array}{l}\text { Ponderador } \\
\text { de dificultad }\end{array}$ & $\begin{array}{c}\text { Proporción } \\
\text { de recursos } \\
\text { a drogas }\end{array}$ & $\begin{array}{c}\text { Costos directos } \\
\text { (millones de } \\
\text { pesos) }\end{array}$ \\
\hline \multirow{2}{*}{$\begin{array}{l}\text { Sistema } \\
\text { policial }\end{array}$} & Carabineros & 320931 & 9870 & 448128 & 1,863 & 4,10 & 13169 \\
\hline & PDI & 86469 & 6468 & 179955 & 1,863 & 6,70 & 5790 \\
\hline \multirow{3}{*}{$\begin{array}{l}\text { Sistema } \\
\text { judicial }\end{array}$} & Ministerio Público & 77878 & 11323 & 1013883 & 1,863 & 2,08 & 1620 \\
\hline & DPP & 29719 & 8741 & 212095 & 1,863 & 7,68 & 2282 \\
\hline & Poder Judicial & 194337 & 25764 & 2193142 & 1,863 & 2,19 & 4253 \\
\hline \multirow{2}{*}{$\begin{array}{l}\text { Sistema } \\
\text { penal }\end{array}$} & GENCHI & 122152 & 12726 & 139333 & - & 9,13 & 11152 \\
\hline & Construcción de cárceles ${ }^{\mathfrak{c}}$ & 3825 & 3468 & 38007 & - & 9,13 & 349 \\
\hline \multirow[t]{4}{*}{ Otros } & SML & 745 & 22757 & 3878160 & - & 17,86 & 989 \\
\hline & UAF & 36440 & 16686 & & - & 0,48 & 133 \\
\hline & Aduanas & & & & - & & 345 \\
\hline & DIRECTEMAR & & & & - & & 157 \\
\hline Total & & & & & & & 40239 \\
\hline
\end{tabular}

Fuente: elaboración propia sobre la base de información de: a M. Olavarría, Estudio nacional sobre costos humanos, sociales y económicos de las drogas en Chile, 2006, Santiago de Chile, Olavarría y Asociados, 2009; Olavarría (2009); b Instituto Nacional de Estadísticas (INE), Anuario de estadísticas policiales. Policía de Investigaciones de Chile, Santiago de Chile, 2008; y Carabineros. Informe anual 2006, Santiago de Chile, 2008; INE (2008a y 2008b); Ministerio Público, Boletín estadístico. Año 2006, Santiago de Chile, Fiscalía Nacional); Ministerio Público (sin año); Defensoría Penal Pública, Informe estadístico. Año 2006, Santiago de Chile; Defensoría Penal Pública (sin año); Poder Judicial, Memoria anual 2006, Santiago de Chile, (2007); Ministerio de Justicia, Compendio estadístico de la población atendida por Gendarmería de Chile, Santiago de Chile, Gendarmería de Chile, Sub Departamento de Estadística y Control Penitenciario, 2006; c Depreciación anual.

UAF: Unidad de Análisis Financiero.

SML: Servicio Médico Legal.

DIRECTEMAR: Dirección General del Territorio Marítimo y Marina Mercante.

CUADRO 14

Costos en control directamente atribuibles al tráfico y consumo de drogas, menores, 2006

(En millones de pesos nominales)

\begin{tabular}{|c|c|c|c|c|c|c|c|}
\hline & & $\begin{array}{l}\text { Presupuesto } \\
\text { total (millones } \\
\text { de pesos)a }\end{array}$ & $\begin{array}{l}\text { Actividades } \\
\text { relacionadas } \\
\text { (número) }\end{array}$ & $\begin{array}{c}\text { Total } \\
\text { actividades } \\
\text { (número) }\end{array}$ & $\begin{array}{l}\text { Ponderador } \\
\text { de } \\
\text { dificultad }\end{array}$ & $\begin{array}{c}\text { Proporción } \\
\text { de recursos } \\
\text { a drogas }\end{array}$ & $\begin{array}{l}\text { Costos directos } \\
\text { (millones de } \\
\text { pesos) }\end{array}$ \\
\hline Sistema policial & Carabineros & 320931 & 2396 & 448128 & 1,863 & 0,53 & 3196 \\
\hline Sistema judicial & Poder Judicial & 194337 & 563 & 2193142 & 1,863 & 0,03 & 93 \\
\hline SENAME & & 53042 & 368 & 5524 & 1 & 6,66 & 3534 \\
\hline Total & & & & & & & 6823 \\
\hline
\end{tabular}

Fuente: elaboración propia sobre la base de información de:

SENAME: Servicio Nacional de Menores.

a M. Olavarría, Estudio nacional sobre costos humanos, sociales y económicos de las drogas en Chile, 2006, Santiago de Chile, Olavarría y Asociados, 2009; Servicio Nacional de Menores (SEnAME), Informe final de evaluación. Programa de Administración Directa, Santiago de Chile, 2007; Olavarría (2009); SENAME (2007); Oficios informales funcionarios SENAME;

b Instituto Nacional de Estadísticas (INE), Carabineros. Informe anual 2006, Santiago de Chile, 2008; INE (2008b Carabineros de Chile/Gobierno de Chile (2007), Programa de Seguridad Integrada para Niños, Niñas y Adolescentes “24 Horas”, Santiago de Chile). 
se hace una estimación a partir de las proporciones de causas con delito especificado sobre el total de causas terminadas (en las causas no resueltas no se especifica el delito). Con ello los recursos destinados a justicia quedan radicalmente subestimados, pues se concluye que hubo 503 menores que ingresaron por delitos de drogas en 2006, lo que —incluido el estimador de dificultad — significa que solo el 0,03\% de los recursos de esta institución se destinan a la indagación de delitos de drogas en menores, es decir, 93 millones de pesos anuales. Esta subestimada cifra viene compensada por la magnitud de los recursos destinados por el SENAME, una institución en principio no punitiva que también depende del Ministerio de Justicia.

- El sename tiene, en materia delictual, una función más rehabilitadora que punitiva; empero, debe hacerse cargo de la internación o seguimiento de menores infractores total o parcialmente privados de libertad. También para el sENAme hay dificultades en la estimación de costos, ya que si bien la información de los menores atendidos es pública, no existe información presupuestaria confiable destinada a menores infractores, puesto que no existía una división institucional respectiva antes de la entrada en vigencia de la ley de RPJ. La información presupuestaria utilizada corresponde a una reconstrucción de distintas informaciones enviadas por funcionarios del SENAME y a la información presentada por la institución en el Informe Final de Evaluación del Programa de Administración Directa (SEnAme, 2007). Con esto, se estima que en 2006 el sename gastó 3.534 millones de pesos en menores que cometieron delitos vinculados a drogas (véase el cuadro 14).

\section{c) Costos indirectos en control: adultos}

Como ya se mencionó, uno de los aspectos más robustos de este artículo es la estimación de costos indirectos en el control de la droga a partir del reciente artículo de fracciones atribuibles de Valenzuela y Larroulet (2010) y de fuentes de información detalladas sobre los delitos asociados por parte de las distintas instituciones comprometidas.

Como se advierte en el cuadro 15, en el país durante el año 2006 las principales instituciones comprometidas en el control delictual gastaron 67.508 millones de pesos en el control de delitos cometidos a causa de la droga por parte de mayores de 18 años, sea para conseguirla (en el caso de los dependientes), bajo sus efectos (cuando el delito no se hubiese cometido) o en el mercado de la droga, siguiendo el modelo tripartito de Goldstein.

Las instituciones que más gastan en control de delitos asociados son Gendarmería (23.658 millones de pesos) y Carabineros de Chile (17.193 millones de pesos). Le siguen la PDI (10.224 millones de pesos)

CUADRO 15

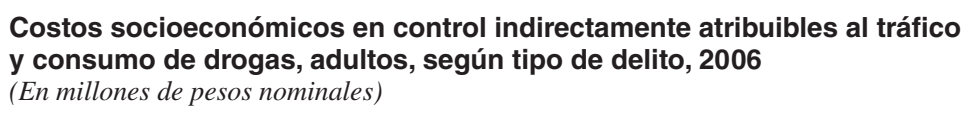

\begin{tabular}{|c|c|c|c|c|c|c|}
\hline & & Robo simple & Robo con violencia & Delitos sexuales & Homicidios & Total \\
\hline \multirow[t]{3}{*}{ Sistema judicial } & Ministerio Público & 6874 & 2276 & 227 & 26 & 9403 \\
\hline & DPP & 1859 & 731 & 87 & 59 & 2736 \\
\hline & Poder Judicial & 2414 & 949 & 113 & 77 & 3552 \\
\hline \multirow{2}{*}{ Sistema policial } & Carabineros & 14637 & 2353 & 120 & 83 & 17194 \\
\hline & PDI & 6239 & 2354 & 1217 & 416 & 10225 \\
\hline \multirow{2}{*}{ Sistema penal } & Gendarmería & 15338 & 7292 & 367 & 660 & 23658 \\
\hline & Construcción de cárceles & 480 & 228 & 12 & 21 & 741 \\
\hline Total & & 47841 & 16184 & 2142 & 1341 & 67508 \\
\hline
\end{tabular}

Fuente: elaboración propia sobre la base de información de M. Olavarría, Estudio nacional sobre costos humanos, sociales y económicos de las drogas en Chile, 2006, Santiago de Chile, Olavarría y Asociados, 2009; Instituto Nacional de Estadísticas (INE), Anuario de estadísticas policiales. Policía de Investigaciones de Chile, Santiago de Chile, 2008; y Carabineros. Informe anual 2006, Santiago de Chile, 2008; Ministerio Público, Boletín estadístico. Año 2006, Santiago de Chile, Fiscalía Nacional.); Defensoría Penal Pública, Informe estadístico. Año 2006, Santiago de Chile; Poder Judicial, Memoria anual 2006, Santiago de Chile, 2007; Ministerio de Justicia, Compendio estadístico de la población atendida por Gendarmería de Chile, Santiago de Chile, Gendarmería de Chile, Sub Departamento de Estadística y Control Penitenciario, 2006; y E. Valenzuela y P. Larroulet, "La relación droga y delito: una estimación de la fracción atribuible", Estudios públicos, N 119, Santiago de Chile, Centro de Estudios Públicos, 2010. 
y el Ministerio Público (9.403 millones de pesos). Si se segrega por delitos, el más relevante es por lejos el robo simple cometido a causa de la droga, que representa para las instituciones de control un costo de 47.841 millones de pesos, es decir, el $71 \%$ de los costos por delitos asociados. Muy lejos le sigue robo con violencia (16.183 millones de pesos), delitos sexuales (2.142 millones de pesos) y homicidios (1.341 millones de pesos).

El método de cálculo es igual al expuesto en la sección de costos directos, salvo que en este caso se incluye el factor de fracciones atribuibles.

\section{d) Costos indirectos en control: menores}

En la estimación de costos indirectos en menores se han empleado las mismas estrategias expuestas previamente en la estimación de costos directos para igual población, debido a las falencias de información disponible. Nuevamente, por lo tanto, se ha subestimado considerablemente el costo de justicia. En el cálculo se agrega el factor de la fracción atribuible para cada delito, que es específico a la población menor de edad (Valenzuela y Larroulet, 2010).

En su conjunto, las instituciones consideradas gastaron 11.719 millones de pesos en el control de delitos cometidos a causa de la droga. La institución que más costos compromete por este motivo es el SENAME con 7.382 millones de pesos, seguido de Carabineros de Chile con 4.231 millones de pesos, y el Poder Judicial con 106 millones de pesos, cifra que está fuertemente subestimada.

Por delito, es nuevamente el robo simple cometido a causa de la droga el que representa más costos al sistema de control (6.362 millones de pesos, o sea, el $54 \%$ ), aunque esta supremacía es menos marcada que en adultos. Le sigue relativamente cerca el costo por robos con violencia e intimidación cometidos a causa de la droga (5.244 millones de pesos, es decir, el 45\%), y de lejos el costo por homicidios (73 millones de pesos) y delitos sexuales (38 millones de pesos), que representan una cifra insignificante en esta población (1\% del total entre ambos) (véase el cuadro 16).

\begin{tabular}{|c|c|c|c|c|c|c|}
\hline & & $\begin{array}{l}\text { Costo socio- } \\
\text { económico de } \\
\text { robo simple }\end{array}$ & $\begin{array}{l}\text { Costo socio- } \\
\text { económico de } \\
\text { robo c/violencia }\end{array}$ & $\begin{array}{l}\text { Costo socio- } \\
\text { económico de } \\
\text { delitos sexuales }\end{array}$ & $\begin{array}{l}\text { Costo socio- } \\
\text { económico de } \\
\text { homicidios }\end{array}$ & $\begin{array}{c}\text { Costo } \\
\text { indirecto atribuible } \\
\text { a SPA }^{\mathrm{a}}\end{array}$ \\
\hline Sistema judicial & Poder Judicial & 44 & 62 & 0,378 & 0,165 & 106 \\
\hline Sistema policial & Carabineros & 1952 & 2279 & - & - & 4231 \\
\hline SENAME & & 4366 & 2904 & 38 & 73 & 7382 \\
\hline Total & & 6362 & 5245 & 38 & 73 & 11719 \\
\hline
\end{tabular}

Fuente: elaboración propia sobre la base de información del Poder Judicial, Memoria anual 2006, Santiago de Chile, 2007; Carabineros de Chile/Gobierno de Chile (2007), Programa de Seguridad Integrada para Niños, Niñas y Adolescentes "24 Horas", Santiago de Chile; Instituto Nacional de Estadísticas (INE, 2008b), Carabineros. Informe anual 2006, Santiago de Chile.

a Sustancias psicoactivas. 


\section{IV}

\section{Conclusiones}

El propósito de este artículo es hacer visible que la carga económica del consumo y tráfico de drogas ilícitas en Chile durante el año 2006 alcanzó al menos a los 266.744 millones de pesos corrientes de ese año, correspondientes a 207.531 millones de pesos actuales (al 30 de abril de 2011). La mayor parte de esta suma se debe a pérdidas de productividad y al control de delitos, sea por infracciones a la ley 20.000 o por delitos de otra naturaleza cometidos a causa de la droga. Las pérdidas directamente atribuibles al consumo y tráfico de drogas se estiman en 173.708 millones de pesos, mientras que los costos indirectos en 93.036 millones de pesos (véase el cuadro 17).

Estos resultados se han obtenido usando la perspectiva de cor para evaluar la repercusión que el consumo y tráfico de drogas representan para el conjunto de la sociedad. Este indicador de "externalidad negativa" pretende servir de base tanto para la toma de decisiones como para el análisis de efectividad de programas y políticas públicas tendientes a reducir el tráfico de drogas, su consumo y sus efectos negativos en el conjunto de la sociedad. Además, un estudio semejante permite transparentar públicamente información que suele no estar disponible para investigadores y público en general, sea por no estar publicada o estar categorizada de manera no unificada por distintas instituciones.

Las estimaciones presentadas presentan falencias que ya han sido destacadas. En la medida que estas obedecen a déficits de información ponen de manifiesto

CUADRO 17

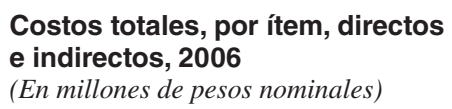

Costos totales, por ítem, directos e indirectos, 2006

(En millones de pesos nominales)

\begin{tabular}{lrcr}
\hline & Directos & Indirectos & Total \\
\hline Prevención & 13070 & & 13070 \\
Salud pública & 5093 & & 5093 \\
Pérdidas de productividad & 108484 & 13810 & 122293 \\
Control (adultos y menores) & 47062 & 79227 & 126288 \\
$\begin{array}{l}\text { Total } \\
\text { Total ajustado al 30 de abril } \\
\text { de 2011 }\end{array}$ & 173708 & 93036 & 266744 \\
\hline
\end{tabular}

Fuente: elaboración propia. la necesidad de estudios específicos en el país para el logro de una estimación más precisa, que permita una cuantificación más realista del problema. Con tal objetivo, a continuación se enumeran los principales requerimientos globales:

i. Idealmente, todas las instituciones del Estado debieran proveer información precisa y detallada, aunque esto resulta urgente para el sistema público de salud, el Poder Judicial y Gendarmería. El sistema de salud pública debe separar los ítems presupuestarios reportados públicamente entre alcohol y drogas y poner a disposición no solo información presupuestaria referida a la atención hospitalaria, sino también primaria, especialmente para evaluar el costo del tratamiento de enfermedades causadas por el consumo de drogas distintas de la drogodependencia. Además, sería deseable contar con un sistema de registro unificado de intervenciones y tratamientos en salud privada, que permita conocer la cantidad de tratamientos por drogodependencia y enfermedades asociadas que se llevan a cabo. El Poder Judicial debe dar información más detallada de sus acciones y su presupuesto respectivo, mientras que Gendarmería debiese disponer de un registro claro de delitos que se correspondan con el criterio judicial, y de una caracterización confiable de las personas atendidas de acuerdo con el tipo de delito que se les asigna.

ii. El país debiese generar un catastro exhaustivo de las ONG involucradas en el tratamiento de drogas ilícitas, distinguiendo las fracciones presupuestarias autónomas de aquellas recibidas de parte del gobierno.

iii. Chile debe incentivar el desarrollo de estudios de fracciones etiológicas que permitan establecer el grado de relación existente entre el consumo de drogas y conductas o consecuencias asociadas, especialmente para el caso de salud. Como muestran los Estados Unidos de América, Australia y el Canadá, estos estudios proporcionan información de gran utilidad para realizar intervenciones de política pública, permitiendo focalizar las intervenciones y los recursos en aquellas sustancias que generan más efectos adversos agregados.

iv. Más globalmente, el país requiere estudios semejantes y con criterios unificados para evaluar 
los costos del consumo de tabaco y alcohol, que permitan comparar sus consecuencias y focalizar e integrar las intervenciones. Una metodología unificada permite, como en Australia y el Canadá, comparar los efectos adversos de cada sustancia y con ello decidir justificadamente hacia dónde dirigir los recursos de prevención y rehabilitación. Pese a que las agencias gubernamentales de drogas ilegales suelen dar gran importancia a su consumo y potencial efecto, estos estudios han servido de base para evaluar más fundadamente y con menos prejuicios la carga que cada droga representa para la sociedad. No hay razones a priori para considerar que la prevención y rehabilitación en drogas ilegales merezcan más atención que en drogas legales. Es posible que en Chile, por ejemplo, así como los programas deben enfocarse en drogas ilegales como la pasta base, más globalmente debieran hacerlo en alcohol, cuya publicidad es permitida y su gravamen comparativamente menor si se lo compara con el tabaco, pese a generar múltiples formas de violencia y más AVISA perdidos que este, tanto directa como indirectamente.

Mediante estos avances, Chile contaría con instrumentos de altos estándares que permitirían justipreciar la magnitud de los problemas vinculados al consumo y tráfico de drogas y establecer una línea de base sólida para el análisis de costo-beneficio de las intervenciones públicas en la materia.
Allende, C. y E. Valenzuela (2008), "Programa 24 horas: Evaluación de una estrategia", Camino al Bicentenario. Propuestas para Chile, I. Irarrázabal y M. Morandé, Santiago de Chile, Pontificia Universidad Católica de Chile.

Carabineros de Chile/Gobierno de Chile (2007), Programa de Seguridad Integrada para Niños, Niñas y Adolescentes "24 Horas", Santiago de Chile.

CICAD (Comisión Interamericana para el Control del Abuso de Drogas) (2006), Pautas metodológicas para estudios de impacto económico del abuso en el consumo de sustancias psicoactivas, Washington, D.C., Organización de los Estados Americanos (OEA).

Collins, D.J. y H.M. Lapsley (2008), The Costs of Tobacco, Alcohol and Illicit Drug Abuse to Australian Society in 2004/05, Canberra, Commonwealth of Australia.

CONACE (Consejo Nacional para el Control de Estupefacientes) (2007), Segundo estudio nacional de drogas en población penal, Santiago de Chile, Consejo Nacional para el Control de Estupefacientes.

(2006), Séptimo estudio nacional de drogas en población general de Chile, Santiago de Chile.

(2005), Estudio de costos asociados al consumo y tráfico de SPA ilegales en Chile para el año 2003, Santiago de Chile.

CONACE/CIGES (Consejo Nacional para el Control de Estupefacientes/ Centro de Capacitación, Investigación y Gestión para la Salud Basada en Evidencia) (2001), Estudio de consumo de drogas en consultantes de los servicios de urgencia, Santiago de Chile.

Defensoría Penal Pública (s/f), Informe estadístico. Año 2006, Santiago de Chile.

Dirección de Presupuestos (2007), Informe final de evaluación. Programa de Administración Directa, Santiago de Chile, Ministerio de Justicia, Servicio Nacional de Menores.

Escuela de Medicina (2008), Estudio de carga de enfermedad y carga atribuible 2007, Santiago de Chile, Departamento de Salud Pública, Pontificia Universidad Católica de Chile.

García-Altés, A., J.M. Ollé y J. Colom (2002), "The social cost of illegal drug consumption in Spain", Addiction, vol. 97, No 9.

Godfrey, C. y otros (2002), "The economic and social costs of class. A drug use in England and Wales, 2000", Home Office Research Study, $\mathrm{N}^{\circ} 249$, Londres, Home Office.

Goldstein, P. (1985), "The drugs/violence nexus. A tripartite conceptual framework", Journal of Drug Issues, vol. 39.

INE (Instituto Nacional de Estadísticas) (2008a), Anuario de estadísticas policiales. Policía de Investigaciones de Chile, Santiago de Chile. (2008b), Carabineros. Informe anual 2006, Santiago de Chile.

Kopp, P. (2001), Calculating the Social Cost of Illicit Drugs. Methods and Tools for Estimating the Social Cost of the Use of Psychotropic Substances, Estrasburgo, Consejo de Europa.

Kopp, P. y F. Philippe (2006), Le coût social des drogues en 2003: les dépenses publiques dans le cadre de la lutte contre les drogues en France en 2003, Paris, Observatoire français des drogues et des toxicomanies.

Longo, M.C. y otros (2000a), "The prevalence of alcohol, cannabinoids, benzodiazepines and stimulants amongst injured drivers and their role in driver culpability. Part I: The prevalence of drug use in drivers, and characteristics of the drug-positive group", Accident Analysis and Prevention, vol. 32, Amsterdam, Elsevier.

(2000b), "The prevalence of alcohol, cannabinoids, benzodiazepines and stimulants amongst injured drivers and their role in driver culpability. Part II: The relationship between drug prevalence and drug concentration, and driver culpability", Accident Analysis and Prevention, vol. 32, Amsterdam, Elsevier.

Ministerio de Justicia (2006), Compendio estadístico de la población atendida por Gendarmería de Chile, Santiago de Chile, Gendarmería de Chile.

Ministerio Público (s/f), Boletín estadístico. Año 2006, Santiago de Chile, Fiscalía Nacional.

OEA/CICAD (Organización de los Estados Americanos/Comisión Interamericana para el Control del Abuso de Drogas) (2006), Estudio de costos humanos, sociales y económicos de las drogas.

Oficina Nacional de Fiscalización de Drogas (2004), The Economic Costs of Drug Abuse in the United States, 1992-2002, Washington, D.C., Executive Office of the President.

Olavarría, M. (2009), Estudio nacional sobre costos humanos, sociales y económicos de las drogas en Chile, 2006, Santiago de Chile, Olavarría y Asociados.

Pacula, R.L. y otros (2009), Issues in Estimating the Economic Cost of Drug Abuse in Consumming Nations, RAND Corporation [en línea] http://www.rand.org/pubs/technical_reports/TR709.html.

Poder Judicial (2007), Memoria anual 2006, Santiago de Chile.

Rehm, J. y otros (2006), The Costs of Substance Abuse in Canada 2002, Ottawa, Canadian Centre on Substance Abuse.

Ridolfo, B. y C. Stevenson (2001), The Quantification of Drug-caused Mortality and Morbidity in Australia, 1998, Canberra, Australian Institute of Health and Welfare.

Segel, J.E. (2006), Cost-of-Illness Studies-A Primer, RTI International. 
SENAME (Servicio Nacional de Menores) (2007), Informe final de evaluación. Programa de Administración Directa, Santiago de Chile, Ministerio de Justicia.

(2006), Estudio de prevalencias de consumo y factores asociados en población infractora adolescente, Santiago de Chile, Instituto de Sociología, Pontificia Universidad Católica de Chile.
Single, E. y otros (2003), International Guidelines for Estimating the Costs of Substance Abuse, Washington, D.C., Organización Mundial de la Salud.

Valenzuela, E. y P. Larroulet (2010), "La relación droga y delito: una estimación de la fracción atribuible", Estudios públicos, $\mathrm{N}^{\circ} 119$, Santiago de Chile, Centro de Estudios Públicos. 